\title{
Yoğun Bakım, Nörolojik Hastalıklar ve Palyatif Bakım için Zamanlama
}

\section{Timing for Intensive Care, Neurological Diseases and Palliative Care}

Arzu Yıldırım Ar ${ }^{1}$

Tamer Bayram²,

Güldem Turan²

${ }^{1}$ T.C. Sağlık Bilimleri Üniversitesi Fatih Sultan Mehmet SUAM Anesteziyoloji ve Reanimasyon Kliniği, Istanbul

${ }^{2}$ T.C. Sağlık Bilimleri Üniversitesi Fatih

Sultan Mehmet SUAM Yoğun Bakım Kliniği, Istanbul

Geliş Tarihi/Received: 15 Ocak 2019 Kabul Tarihi/Accepted: 8 Ağustos 2019

Yazışma Adresi: Arzu Yıldırım Ar, Sağlık Bilimleri Üniversitesi Fatih Sultan Mehmet SUAM Anesteziyoloji ve Reanimasyon Kliniği C blok 5. Kat E5 yolu üzeri Ataşehir/Istanbul e-posta: dr.arzuyildirim@hotmail.com

\section{ORCID}

Arzu Yıldırım Ar

https://orcid.org/0000-0002-5867-0897

Tamer Bayram

https://orcid.org/0000-0003-0417-3542

Güldem Turan

https://orcid.org/0000-0002-7281-1705

\section{GíRiş}

Nörolojik hastalar; akut serebrovasküler olayın (SVO) neden olabileceği bilinç gerilemesi nedeniyle ya
Öz

Amaç: Nörolojik hastalığı olanlar; çeşitli nedenlerle gelişen solunum yetmezliği sonucu yoğun bakım desteğine intiyaç duyabtilirler. Bazıları yoğun bakım destek tedavilerinden fayda görürken bazıları da bakım hastası olarak yaşamlarına devam etmekte ya da rehabilitasyon programlarına ihtiyaç duymaktadır. Yoğun bakımda tedavi süreleri uzayan her hastanın gerektiğinde palyatif bakım ya da rehabilitasyon merkezlerine yönlendirilme ve eve çıkış süreçlerinin iyi yönetilmesi yoğun bakım yataklarının akılcı kullanımı açısından önemlidir.

Hastalar ve Yöntem: Fatih Sultan Mehmet SUAM bilimsel çalışmalar kurulunun 17073117-050.06 karar numaralı izni alınarak Ocak 2017-Mayıs 2018 tarihleri arasında yoğun bakım kliniğine primer nörolojik hastalıklar ön tanısıyla yatırılıp eksitus ile sonlanan veya eve/palyatif bakıma yönlendirilen hastalarımızın verilerini retrospektif olarak değerlendirdik. Diğer kliniklere devir edilen hastalar çalışmaya dahil edilmedi. Hastaların APACHE II, SAPS II skorları, yatış günü, mekanik ventilasyon süreleri, trakeostomi ve Perkütan Endoskopik Gastrostomi gereksinimi, ev tipi ventilatör temini ve yoğun bakımdan çıkış şekilleri kaydedildi. Bulgular: Toplam 942 hasta dosyası tarandı hastaların 74'ü nörolojik hastalıklar nedeniyle yatarken eks olan veya direkt ev/palyatif bakıma transfer olan hastalardı. Nörolojik hastalıklardan dolayı yatan 74 hastanın 30 (\%40.5) unda ağır demans 21(\%28.3) inde iskemik inme $23(\% 68,8)$ ünde ise diğer nörolojik problemler bulunmaktaydı. Bu 74 hastanın 60(\%81.1)' i yatarken eks oldu, palyatif bakıma yönlendirilen hasta sayısı ise $5(\% 6,8)$ idi.

Sonuç: Yoğun bakımdan palyatif bakıma zamanında geçiş oranlarının artırılması yoğun bakım yataklarının etkin kullanımı açısından önemlidir. Bu nedenle yoğun bakım hastalarının, gerektiğinde palyatif bakıma yönlendirilmesi açısından belirli aralıklarla değerlendirilmesi önerilir.

Anahtar Kelimeler: Nörolojik hastalık, palyatif bakım, yoğun bakım ünitesi, mekanik ventilasyon süreleri, trakeostomi

\section{Abstract}

Aim: Patients with neurological diseases may require intensive care support as a result of respiratory failure due to various reasons. Some of them benefit from intensive care supportive treatment while others continue to live as caregivers or need rehabilitation programs. It is important for the rational use of intensive care beds that the routing process to the palliative care, rehabilitation centers or discharge of patients with prolonged treatment in the intensive care unit should be managed well

Patients and Methods: We retrospectively evaluated the data of our patients who were hospitalized with the diagnosis of primary neurological diseases in the intensive care unit and terminated with exitus or referred to home / palliative care between January 2017 and May 2018 with the permission (17073117050.06 decision no) of Fatih Sultan Mehmet health application and research center scientific studies committee. Patients who transferred to other clinics were excluded from the study. APACHE II/SAPS II scores, hospitalization day, mechanical ventilation time, tracheostomy and percutaneous endoscopic gastrostomy requirement, home ventilator supply and the situation of discharge from intensive care unit of patients were recorded

Results: A total of 942 patient files were reviewed retrospectively and 74 (7.8\%) of our patients were neurological patients who were died or discharged to directly homelpalliative care. Most of the patients in the study had severe dementia (30 patients, $40.5 \%$ ) and fewer number of patients had ischemic stroke (21 patients, $28.3 \%)$. Sixty of the 74 patients $(81.1 \%)$ died in the intensive care unit. Only 5 patients were transferred to palliative care $(6.8 \%)$.

Conclusion: Increasing transfer from intensive care to palliative care is important for the effective use of intensive care beds. Therefore, it is suggested that intensive care patients should be evaluated periodically to be directed to palliative care

Keywords: Intensive care unit; neurological disease; palliative care, mechanical ventilation time, tracheostomy
Atıf yapmak için: Yıldırım Ar A, Bayram T, Turan G. Yoğun bakım Nörolojik Hastalıklar ve Palyatif Bakım için Zamanlama. Selcuk Med J 2020;36(1): $1-5$ da progresif seyreden nörodejeneratif, nöromusküler hastalıkların akut komplikasyonları sonucu gelişen solunum yetersizliği nedeniyle yoğun bakım 
yataklarının önemli bir kısmını oluşturmaktadırlar. Bu hastaların büyük bölümü ya bakım hastası olarak yaşamlarına devam etmekte ya da uzun süreçli rehabilitasyon programlarına intiyaç duymaktadır. Hastaların gerektiği zaman palyatif bakıma ya da rehabilitasyon merkezlerine yönlendirilmemesi durumunda, tedavi süreçlerini yoğun bakım kliniklerinde geçirilmesine neden olmaktadır. Böyle bir durum yoğun bakım yataklarının etkin kullanım prensibine uygun değildir. Bu nedenle hastaların palyatif bakıma, rehabilitasyon merkezlerine ve eve çıkış süreçlerinin iyi yönetilmesi gerekmektedir (1).

Palyatif bakım, ilerleyici ve tedavisi olmayan hastalık/hasta veya ölümcül hastalıklarda yaşam kalitesini artırmaya yönelik bir bakım sistemidir. $\mathrm{Bu}$ bakım ciddi ve ilerlemiş hastalık durumları olan bireylerin yaşam kalitesini artırmaya odaklanan tanı anı dahil tedavinin herhangi bir aşamasında uygulanan bakım sürecidir. Parkinson hastalığı, demans, Amyotrofik Lateral Skleroz (ALS), inme, beyin tümörü gibi çeşitli nörolojik hastalıklar tanı veya tedavilerinin herhangi bir döneminde fiziksel, psikolojik, sosyal ve manevi bakımı kapsayan palyatif bakıma intiyaç duyarlar (2-4). Yoğun bakım sürecinde hastalar her gün palyatif bakıma geçiş açısından değerlendirilir ve kronik kritik hastalık durumu, hayatı sınırlayan hastalığa sahip hastalarda destek uygulamalara geçilmesi durumunda (trakeostomi, perkutan endoskopik gastrostomi (PEG) vb), ileri yaş, önemli komorbidite varlığı ve başlangıçta zayıf işlevsel durum, tedavi edilemeyen hastalık varlığı (metastatik kanser, ALS, vb) uzun süren yatışlar, klinisyen tarafından medikal tedavinin faydasız olduğu düşünülen durumlarda palyatif bakıma geçiş olabilir (5).

Biz bu çalışmamızda 0cak 2017-Mayıs 2018 tarihleri arasında 20 yataklı 3 . basamak yoğun bakım kliniğimizde nörolojik hastalıklar nedeniyle yatan hastaların takip dönemlerini, klinikten çıkış süreçlerinin özelliklerini ve palyatif bakıma geçiş oranlarını sunarak yoğun bakım yataklarının daha etkili kullanımına dikkat çekmek istedik.

\section{HASTALAR VE YÖNTEM}

Hastanemiz bilimsel çalışmalar kurulu izni (17073117-050.06) alınarak; Ocak 2017-Mayıs 2018 tarihleri arasında yoğun bakım kliniğimize nörolojik hastalıkların sebep olduğu nedenlerle yatırılarak tedavi olan 942 hastadan eks olan veya eve/palyatif bakıma direkt çıkan hastaların verilerini retrospektif olarak değerlendirdik. İmmobil, tedavi edilebilir olmayan başkasının desteğine intiyacı olan hastalar palyatif bakım açısından günlük değerlendirildi. Hemodinamisi stabil, enfeksiyon bulgusu olmayan solunumu spontan ya da ev tipi ventilatörle güvenli olarak sağlanabilen günlük kalori intiyacı tam olarak karşılanabilen hastalar palyatif bakıma transferi uygun görüldü. Hastane içinde diğer kliniklere devir edilen hastalar çalışmaya dahil edilmedi. Hastaların APACHE II, SAPS II skorları, yatış günü, komorbidite sayıları, mekanik ventilasyon (MV), Noninvaziv mekanik ventilasyon (NIMV) süreleri, enteral beslenme durumları trakeostomi ve PEG gereksinimi, ev tipi ventilatör temini, spontan solunuma geçme ve yoğun bakımdan çıkış şekilleri kaydedildi.

Çalışmada elde edilen bulgular değerlendirilirken, istatistiksel analizler için IBM SPSS Statistics 22 (IBM SPSS, Türkiye) programı kullanıldı. Çalışma verileri değerlendirilirken parametrelerin normal dağılıma uygunluğu Shapiro Wilks testi ile değerlendirilmiştir. Çalışma verileri değerlendirilirken tanımlayıcı istatistiksel metodlar (Ortalama, Standart sapma, medyan, frekans) kullanıldı. Anlamlılık $p<0.05$ düzeyinde değerlendirildi.

Tablo 1. Olguların Yaş, Komorbidite sayısı, APACHE II, SAPS II, SOFA, yatış gün sayısı, mekanik ventilasyon, non invaziv mekanik ventilasyon gün süreleri, Trakeostomi açılma zamanının değerlendirilmesi

\begin{tabular}{lll}
\hline & Min-Max & OrttSS \\
\hline Yaş & $36-94$ & $77,81 \pm 12,83$ \\
Komorbidite sayısı (medyan) & $0-5$ & $1,89 \pm 1,07(2)$ \\
APACHE II & $8-44$ & $23,97 \pm 7,66$ \\
SAPS II & $9-96$ & $53,69 \pm 19,71$ \\
SOFA (medyan) & $1-22$ & $6,09 \pm 3,82(5)$ \\
Yatış gün sayısı (medyan) & $0-96$ & $24,57 \pm 23,98(16)$ \\
MV süresi/gün (medyan) & $0-91$ & $22,82 \pm 23,39(14)$ \\
NIMV süresi/gün (medyan) & $0-19$ & $0,61 \pm 2,58(0)$ \\
Trakeostomi açılma zamanı (n=30) (medyan) & $2-49$ & $15,17 \pm 8,29(13,5)$ \\
\hline
\end{tabular}

MV: Mekanik ventilasyon, NIMV: Noninvaziv mekanik ventilasyon 
Tablo 2. Olguların Primer tanılarının değerlendirilmesi

\begin{tabular}{llll}
\hline & $\mathbf{n}$ & $\%$ \\
\hline Primer tanı & İskemik inme (SVO) & 21 & 28,4 \\
& Parkinson+demans & 3 & 4,1 \\
& Hemorajik inme (SVO) & 8 & 10,8 \\
Demans & 30 & 40,5 \\
Multipl sklerozis (demyelinizan hastalıklar) & 1 & 1,4 \\
SAK & 6 & 8,1 \\
Demans+SVO & 4 & 5,4 \\
& SVO+Parkinson & 1 & 1,4 \\
\hline
\end{tabular}

SAK: Subaraknoid kanama

\section{BULGULAR}

$\mathrm{Bu}$ dönemde yoğun bakıma yatan toplam 942 hasta dosyası tarandı. Yaşları 36 ile 94 arasında değişmekte olan, 36'sı (\%48.6) erkek ve 38'i (\%51.4) kadın olmak üzere toplam 74 hastamız (\%7.8) nörolojik nedenle yatan eks olan veya direkt olarak ev/palyatif bakıma çıkan hastalardı. Olguların yaş ortalaması $77,81 \pm 12,83$, ortalama MV süresi $22,82 \pm 23,39$, NIMV süresi ise $0,61 \pm 2,58$ gündü. Ortalama trakeotomi açılma zamanı 15,17 $\pm 8,29$ gün idi. Olguların yaş, APACHE II, SAPS II, SOFA, yatış gün süre, komorbidite sayısı, MV, NIMV gün süreleri trakeotomi açılma zamanı ortalamaları Tablo 1 ' dedir. Demans 30(\%40,5) hastada saptanarak en fazla görülen primer tanı idi. iskemik inme $21(\% 28,4)$ hastada, hemorajik inme ise $8(\% 10,8)$ hastada gözlendi. Olguların primer tanılarını değerlendirilmesi Tablo 2'dedir. Hastalardan 30(\% 40,5)' una trakeostomi açıldı, ev tipi ventilatör $15(\% 20,3)$ hastaya yazıldı. Enteral beslenme durumu 59(\%79,7), PEG açılımı 13(17,6) hastada saptandı. Hastalardan Parkinson+Demans primer tanılı 2 hasta, demans ve subaraknoid kanama tanılı birer hasta olmak üzere toplam 4 hastada başarılı weaning görülerek spontan solunuma dönüş gözlendi. Bu hastaların weaning süreleri 24-48 saat idi. Hastaların trakeostomi, PEG açılımı, ev tipi ventilatör yazılımı, enteral beslenme durumu ve çıkış şekillerinin değerlendirilmesi Tablo 3' dedir. Hastalıklara göre komorbidite sayısı, MV süresi, trakeostomi açılma süreleri'nin değerlendirilmesi Tablo 4'de ayrıca enteral beslenme, mortalite ve PEG açılımı'nın değerlendirilmesi de Tablo 5'dedir. Oral alıma geçen hasta saptanmadı. Eksitus olan hasta sayısı $60(\% 81,1)$, eve transfer ettiğimiz hasta sayısı $9(\% 12,2)$ ve palyatif bakıma transfer ettiğimiz hasta sayımız $5(\% 6,8)$ idi.

\section{TARTIŞMA}

Nörolojik kaynaklı yoğun bakım yatışı olan hastaların yaş ortalamaları genellikle yüksek ve beraberinde komorbid hastalık sayıları da fazladır. Bizim hastalarımızın da büyük kısmı demans ve serebrovasküler hastalık tanılı olup yaş ortalaması da 70'in üstündedir. Hastalarımızın APACHE II ve SAPS II skorları da yüksektir. Yaş ortalamasının yüksek olması ve komorbidite sayılarının fazla olmasının APACHE ve SAPS skorlarının yüksekliğinde etkili olabileceği kanaatindeyiz Yoğun bakımda ortalama

Tablo 3. Hastaların trakeostomi, ev tipi ventilatör yazılımı, enteral beslenme durumu, Perkütan Endoskopik Gastrostomi ve çıkış şekillerinin değerlendirilmesi

\begin{tabular}{llll}
\hline & & $\mathbf{n}$ & $\%$ \\
\hline Trakeostomi açılımı & Yok & 44 & 59,5 \\
Ev tipi ventilatör yazılımı & Var & 30 & 40,5 \\
& Yok & 59 & 79,7 \\
Enteral beslenme & Var & 15 & 20,3 \\
& Yok & 15 & 20,3 \\
PEG açılımı & Var & 59 & 79,7 \\
Çıkış Şekli & Yok & 61 & 82,5 \\
& Var & 13 & 17,5 \\
& Eksitus & 60 & 81,1 \\
& Eve & 9 & 12,2 \\
\hline
\end{tabular}


yatış süresi 24.5 gündür ve ortalama mekanik ventilatör süreleri 22.8 gündür. 30 hastamıza (\% 40.5) trakeostomi gerekti ve 15 hastamıza $(\% 20,3)$ ev tipi ventilatör temin edildi. 13 hastamıza da (\% 17.5) PEG gereksinimi oldu. Eks olan hasta sayımız $60(\% 81,1)$, palyatif bakıma transfer ettiğimiz hasta sayımız 5 $(\% 6,8)$ idi.

Palyatif bakım intiyacı olan hastaların çok büyük bir kısmını maligniteler oluşturmasına rağmen, son yıllarda giderek artan oranda malignite dışı nedenlerle de palyatif bakım intiyacı olmaktadır (6). Chanine et al. (6) retrospektif olarak yaptıkları çalışmalarında 1 yıl süre ile palyatif bakıma kabul edilen ve konsülte edilen hastaların \% 29.1'ini malign olmayan hastaların oluşturduğunu, bu hastaların \% 30.1'ini de nöroloji veya nörocerrahi hastalarının oluşturduğunu ve bu hastaların palyatif merkezinde 2 . en sık görülen hastalıklar olarak bulmuşlardır. Hastaların yaş ortalamalarını 70 olarak tespit etmişlerdir (6). Yoğun bakımımızda tedavi ettiğimiz hastaların palyatif bakıma geçiş oranını incelediğimiz çalışmamızda Chanine et al. (6) yapmış oldukları çalışmaya benzer şekilde yaş ortalamamı 70 yaş üzeriydi. İlk sırada demans sonrasında benzer şekilde iskemik SVO en fazla görülmüştür.

Creuztzfeldt et al. (7) yaptıkları bir başka çalışmada ise; nöroloji ve beyin cerrahisi yoğun bakım hastalarında palyatif bakım intiyacını belirlemek için günlük 4 soru içeren değerlendirme yapmışlardır. 3 aylık sürede 130 hastaya bu değerlendirme yapılmış, 132 hastaya da değerlendirme yapılmamıştır. Palyatif bakım intiyacı açısından günlük olarak değerlendirilen hastalarda palyatif bakım intiyacı \% 62 (80/130) oranında belirlenmiştir (7). Literatürde belirtildiği gibi yoğun bakım ünitelerinde, palyatif bakım geçiş protokollerinin bulunması hasta ve ailelerin pozitif yaklaşımını etkilemektedir. Bakımın hedeflerini tartışmak kavramsal olarak prognoz hakkında ve kötü prognozu konuşmaktan daha olumlu sonuçlar üretmektedir. Yoğun bakımda kalış süresinde uzama ile aile memnuniyeti azalırken, palyatif bakım veya tedavi çekme yaklaşımlarının anlatıldığı ailelerde memnuniyet oranı artmaktadır (8). Biz Creutzfeldt et al. (7) prospektif olarak yaptıkları gibi günlük değerlendirilen bir test kullanmadık fakat hastalarımız genel palyatif bakım ihtiyacı açısından rutin pratiğimizde değerlendirilmiştir. Yine literatürde belirtildiği gibi yoğun bakımdan palyatif bakıma geçiş yapıldığında; ventilatör gün süresinin, parenteral beslenmenin posttravmatik stres bozukluğunun azaldığı ayrıca yoğun bakım ünitesinde yatış süresinin kısaldığı, hastanede yatış süresinin ve aile anksiyetesinin azaldığı, aile memnuniyetinin arttığı gösterilmiştir (9). Campbell et al. (10) yaptıkları çalışmada yoğun bakımda takip edilen ileri evre demans hastalarında dinamik yaklaşımın etkinliğini incelemişler ve bu tür yaklaşımın bu dönemdeki hastaların bakımını iyileştirdiğini ve kaynak kullanımını artırdığını belirtmişlerdir (10). Hastaların palyatif bakıma geçiş için günlük olarak değerlendirilmesi, yapılması gereken hazırlıklara zamanında başlanması açısından da önemlidir. Endikasyon oluştuğunda hastalara trakeostomi ve PEG gerekli ise; ev tipi ventilatör ve hasta bakımı için gerekli malzemelerin temin edilmesi, palyatif bakıma geçiş için gereken şartlardandır. Bunların temini belirli bir süre alacağı için hastanın palyatif bakıma geçişinde zaman kaybına yol açmamak için planlamaların zamanında ve geç kalınmadan yapılması önemlidir.

Yoğun bakım hastalarında tedavi süreci bittikten sonra hastaların palyatif bakım merkezlerine yönlendirilmesi, yoğun bakım yataklarının etkin

Tablo 4. Primer tanılara göre komorbidite sayısı, mekanik ventilasyon ve trakeostomi sürelerinin değerlendirilmesi

\begin{tabular}{|c|c|c|c|c|c|c|}
\hline \multirow[t]{2}{*}{ Primer tanı } & \multicolumn{2}{|c|}{ Komorbidite sayısı } & \multicolumn{2}{|c|}{ MV süresi (gün) } & \multicolumn{2}{|c|}{ Trakeostomi açılma süresi (gün) } \\
\hline & Min-Max & $\begin{array}{l}\text { Ort } \pm S S \\
\text { (medyan) }\end{array}$ & Min-Max & $\begin{array}{l}\text { Ort } \pm S S \\
\text { (medyan) }\end{array}$ & Min-Max & $\begin{array}{l}\text { Ort } \pm S S \\
\text { (medyan) }\end{array}$ \\
\hline İskemik inme (SVO) & $1-5$ & $2,52 \pm 1,08(3)$ & $1-75$ & $24,62 \pm 23,95(14)$ & $2-18$ & $11,56 \pm 4,82(12)$ \\
\hline Parkinson+Demans & $1-2$ & $1,67 \pm 0,58(2)$ & $0-20$ & $9 \pm 10,15(7)$ & $13-13$ & $13 \pm 0(13)$ \\
\hline Hemorajik inme (SVO) & $1-4$ & $2,25 \pm 1,04(2)$ & $3-87$ & $28,13 \pm 31,51(15)$ & $9-15$ & $12 \pm 4,24(12)$ \\
\hline $\begin{array}{l}\text { Demans } \\
\text { Multipl sklerozis }\end{array}$ & $0-4$ & $1,57 \pm 0,94(1)$ & $2-91$ & $23,63 \pm 24,31(12,5)$ & $7-49$ & $18,92 \pm 11,2(17,5)$ \\
\hline (Demyelinizan hastalıklar) & $0-0$ & $0 \pm 0(0)$ & $33-33$ & $33 \pm 0(33)$ & $21-21$ & $21 \pm 0(21)$ \\
\hline SAK & $1-3$ & $1,67 \pm 0,82(1,5)$ & $3-21$ & $8,83 \pm 6,59(6,5)$ & $12-14$ & $13 \pm 1,41(13)$ \\
\hline Demans+SVO & $0-3$ & $1,5 \pm 1,29(1,5)$ & $9-62$ & $26,25 \pm 24,14(17)$ & $8-17$ & $12,5 \pm 6,36(12,5)$ \\
\hline SVO+Parkinson & $1-1$ & $1 \pm 0(1)$ & $20-20$ & $20 \pm 0(20)$ & $15-15$ & $15 \pm 0(15)$ \\
\hline
\end{tabular}

MV Süresi: Mekanik Ventilasyon süresi, SAK: Subaraknoid Kanama 
Tablo 5. Primer tanılara göre Enteral beslenme, Mortalite ve Perkütan Endoskopik Gastrostomi açılımının değerlendirilmesi

\begin{tabular}{|c|c|c|c|c|c|c|}
\hline \multirow[t]{2}{*}{ Primer tanı } & \multicolumn{2}{|c|}{ Enteral beslenme } & \multicolumn{2}{|l|}{ Mortalite } & \multicolumn{2}{|c|}{ PEG açılımı } \\
\hline & $\begin{array}{l}\text { Yok } \\
\text { n(\%) }\end{array}$ & $\begin{array}{l}\text { Var } \\
n(\%)\end{array}$ & $\begin{array}{l}\text { Yok } \\
\text { n(\%) }\end{array}$ & $\begin{array}{l}\text { Var } \\
\mathrm{n}(\%)\end{array}$ & $\begin{array}{l}\text { Yok } \\
\text { n(\%) }\end{array}$ & $\begin{array}{l}\text { Var } \\
\text { n(\%) }\end{array}$ \\
\hline Iskemik inme (SVO) & $3(\% 14,3)$ & $18(\% 85,7)$ & $3(\% 14,3)$ & $18(\% 85,7)$ & $18(\% 85,7)$ & $3(\% 14,3)$ \\
\hline Parkinson+Demans & $1(\% 33,3)$ & $2(\% 66,7)$ & $2(\% 66,7)$ & $1(\% 33,3)$ & $2(\% 66,7)$ & $1(\% 33,3)$ \\
\hline Hemorajik inme (SVO) & $2(\% 25)$ & $6(\% 75)$ & $1(\% 12,5)$ & $7(\% 87,5)$ & $7(\% 87,5)$ & $1(\% 12,5)$ \\
\hline Demans & $8(\% 26,7)$ & $22(\% 73,3)$ & $6(\% 20)$ & $24(\% 80)$ & $24(\% 80)$ & $6(\% 20)$ \\
\hline $\begin{array}{l}\text { Multipl sklerozis } \\
\text { (Demyelinizan } \\
\text { hastalıklar) }\end{array}$ & $0(\% 0)$ & $1(\% 100)$ & $0(\% 0)$ & $1(\% 100)$ & $1(\% 100)$ & $0(\% 0)$ \\
\hline SAK & $1(\% 16,7)$ & $5(\% 83,3)$ & $1(\% 16,7)$ & $5(\% 83,3)$ & $5(\% 83,3)$ & $1(\% 16,7)$ \\
\hline Demans+SVO & $0(\% 0)$ & $4(\% 100)$ & $0(\% 0)$ & $4(\% 100)$ & $4(\% 100)$ & $0(\% 0)$ \\
\hline SVO+Parkinson & $0(\% 0)$ & $1(\% 100)$ & $1(\% 100)$ & $0(\% 0)$ & $0(\% 0)$ & $1(\% 100)$ \\
\hline
\end{tabular}

PEG:Perkütan Endoskopik Gastrostomi, SAK: Subaraknoid kanama

kullanımı açısından da önemlidir. Hastaların belirli aralıklarla palyatif bakım intiyacı açısından değerlendirilmesi önemlidir. Fakat uygun sayıda yatak sayısı bu transferler etkin kullanılması üzerinde önemli bir faktördür. Hastaların durumlarında; eşlik eden nörolojik durumunun ciddiyeti, yüksek yaş ortalaması, yüksek APACHE II ve SAPSII skorlarının olması gibi multifaktöriyel nedenler yer almaktadırlar. Çalışmamızda mortalite oranımız \%81 gibi yüksek orandadır. Nörolojik nedenlere bağlı olarak yoğun bakım yatışı olup hastane içi diğer kliniklere taburculuğu yapılan hastalarımızın çalışma dışı bırakılması, hastalarımızın yaş ortalamasının yüksek ve ek hastalıklarının fazla olması, primer yatış tanıları incelendiğinde \%40 oranında ileri evre demans ve \%28 oranında büyük damar tutulumuna bağlı serebrovasküler hastalıkları olması ve mekanik ventilatör, yoğun bakım yatış sürelerinin uzun olması nedeniyle mortalite oranlarımızın yüksek çıkmasına neden olmuş olabilir. Çalışmamızda başka kliniğe geçerek tedavi süreci devam eden hastaları dahil etmeme nedenimiz, yoğun bakımlardan palyatif bakıma geçiş oranlarının azlığını daha iyi belirlemek amaçlıdır. Sadece \%6.8 hasta palyatif bakıma geçebilmiştir ve \%12.2 hasta direk eve taburcu edilebilmiştir.

Sonuç olarak; hastaların palyatif bakıma zamanında geçiş oranının artırılması, yoğun bakım süreçlerinin uzamasına bağlı mortalite oranlarının artmasına engel olabileceği gibi yoğun bakım yataklarının daha etkili ve verimli kullanımı açısından da önemli olduğu görüşündeyiz.

Çıkar Çatışması: Çalışmada herhangi bir çıkar çatışması yoktur.
Finansal Çıkar Çatışması: Çalışmada herhangi bir finansal çıkar çatışması yoktur.

Yazışma Adresi: Arzu Yıldırım Ar,

Sağlık Bilimleri Üniversitesi Fatih Sultan Mehmet SUAM Anesteziyoloji ve Reanimasyon Kliniği C blok 5. Kat E5 yolu üzeri Ataşehir/Istanbul

Tel No: 05053822729

E-mail:dr.arzuyildirim@hotmail.com

\section{KAYNAKLAR}

1. Oliver DJ, Borasioc GD, Caracenide A, et. al. A consensus review on the development of palliative care for patients with chronic and progressive neurological disease. European $\mathrm{J}$ Neurology 2016;23:30-8.

2. Robinson MT, Holloway RG. Palliative care in neurology. Mayo Clin Proc 2017;92(10):1592-601.

3. Borasio GD. The role of palliative care in patients with neurological diseases. Nat Rev Neurol 2013;9:292-5.

4. Foley KM, Carver AC. Palliative care in neurology. Neurologic Clinics 2001;19(4):789-99.

5. Weissman DE, Meier DE. Identifying patients in need of a palliative care assessment in the hospital setting. J Palliative Medicine 2011;1(14):1-6.

6. Chahine LM, Malik B, Davis M. Palliative care needs of patients with neurologic or neurosurgical conditions. European J Neurology 2008;15:1265-72.

7. Creutzfeldt CJ, Engelberg RA, Healey L, et. al. Palliative care needs in the Neuro-ICU. Crit Care Med 2015; 43(8):1677-84.

8. Nelson JE, Curtis JR, Mulkerin C, et.al. Choosing and using screening criteria for palliative care consultation in the ICU: A report from the improving palliative care in the ICU (IPAL-ICU) advisory board. Critical Care Medicine 2013;41(10):2318-27.

9. Aslakson R, Cheng J, Vollenweider D, et. al. Evidencebased palliative care in the intensive care unit: A systematic review of interventions. J Palliatıve Medicine 2014;17(2):219-35.

10. Campbell ML, Guzman JA. A proactive approach to improve end-of-life care in a medical intensive care unit for patients with terminal dementia. Crit Care Med 2004; 32(9):1839-43. 